\title{
ESPAÇOS E TEMPOS ESCOLARES: formação continuada de professores
}

\author{
Spaces and times school: continuing teachers education
}

\author{
Maricilda Nazaré Raposo de Barros ${ }^{1}$ \\ Terezinha Valim Oliver Gonçalves ${ }^{2}$
}

\begin{abstract}
RESUMO
Apresentamos um estudo de caso, cujo objetivo foi o de conhecer/compreender a formação continuada dos professores na Escola Cidade de Emaús, desde o início de sua implantação, analisando sua proposta inicial na década de 80 até o ano de 2003. Para isso, entrevistamos professores das diferentes décadas de existência da escola e apresentamos o trabalho na modalidade de pesquisa narrativa. Estabelecemos como elementos norteadores dessa formação a organização de espaços e tempos escolares e as ações formativas na escola.
\end{abstract}

Palavras-chave: formação de professores, espaços e tempos escolares, ações formativas na escola.

\begin{abstract}
We present a case study, whose objective was to know / understand the continuing teachers education in School City of Emmaus, since the beginning of its implementation, analyzing its initial proposal in the 80's until the year 2003 . For this, we interviewed teachers from different decades of existence of the school and presented the work in the narrative research mode. Established as the guiding elements of teaches education the organization of the spaces and times school and educational activities at school.
\end{abstract}

Keywords: teacher education, spaces and times school, educational activities at school.

\section{AS VOZES DE PROFESSORAS DE $1^{\mathrm{a}}$ À $4^{\mathrm{a}}$ SÉRIE DO ENSINO FUNDAMENTAL}

A Escola de Emaús é uma escola de ensino fundamental e médio do Movimento de Emaús, de iniciativa de um sacerdote da Igreja Católica de Belém $/ \mathrm{Pa}$. Esta escola iniciou suas atividades nos anos oitenta. As primeiras discussões com as famílias acerca dos propósitos da escola geraram as primeiras programações de formação de professores (SWIFT, 1998), que foram articuladas pelos militantes do Movimento com a Universidade Federal do Pará, vindo desta IES uma professora para apresentar e discutir a escola, a partir de sua experiência em uma escola montessoriana. A escolha da vertente montessoriana para $\mathrm{o}$ trabalho pedagógico na Escola de Emaús tem, em sua gênese, a presença dessa professora como formadora.

Assim, pais, mães e comunidade reunidos dizem como querem essa escola, seus professores, apontando os caminhos para sua construção e concepção de formação. Como diz Freire (1991), uma escola que se deseja democrática respeita a real participação de todos.

Todas as pessoas têm suas histórias. Para algumas, isso constitui o próprio viver, não só para relembrar, mas também para avaliar o diaa-dia. Nesse avaliar, reside a vontade de reencontrar ideais e reinventar ações que se tornam a cada dia uma necessidade diante de novos fatos sociais, como o desemprego e a violência.

A concepção de uma escola em que o aluno participasse do processo, que tivesse liberdade

\footnotetext{
${ }^{1}$ Mestre em Educação em Ciências e Matemáticas pela Universidade Federal do Pará, Brasil (2004), professora Pesquisadora da Universidade do Estado do Pará, Brasil.

${ }^{2}$ Doutora em Educação pela Universidade Estadual de Campinas (2000), na linha de pesquisa \&quot; Ensino, Avaliação e Formação de Professores\&quot; . Atualmente faz parte do Corpo Editorial da Revista Brasileira de Pesquisa em Educação em Ciências e é professora associada III da Universidade Federal do Pará.
} 
de escolha, a partir dos materiais que lhes iam sendo apresentados, e inserida na vida da comunidade, encontra raízes na perspectiva de Maria Montessori ${ }^{3}$. Márcia, professora chegada à escola em 1984, vinda de uma escola de formação de professores, se entusiasma com os materiais montessorianos utilizados, também, no trabalho de formação dos professores, além da aprendizagem das crianças e adolescentes da recém implantada Escola de Emaús, contribuindo para alterar o modo de algumas professoras "enxergarem" a Matemática. Como diz a Prof ${ }^{\mathrm{a}}$ Márcia:

\section{[...] quando eu cheguei aqui foi que eu comecei a buscar [superar] aquela coisa [antipatia] que eu tinha com a matemática; eu comecei a perder aqui, através dos jogos, [...] quando eu comecei aqui, tinham muitos jogos. Quando eu comecei, estava naquela época que ainda tinha muitos jogos montessorianos, ai eu fui simpatizando [com a matemática] (Prof ${ }^{\mathrm{a}}$ Márcia, entrevista, 2003).}

Com a Escola em funcionamento, foi oferecido aos docentes um curso de 150 horas no Método Montessori, orientado por professores do Rio de Janeiro, financiado pela Fundação de Amparo e Desenvolvimento da Pesquisa FADESP/UFPA. Além desse curso, foi garantido um ciclo de estudos em Língua Portuguesa e Matemática por uma escola montessoriana local. (HORA, 1994).

A formação destacada acima envolveu tanto os novos professores da Escola quanto outros profissionais da comunidade, como lembra a Prof ${ }^{\mathrm{a}}$ Alice:

\begin{abstract}
Antes de vir pra cá transferida, uma das coisas que mais me chamou a atenção quando eu cheguei aqui no bairro do Benguí [...] não queria trabalhar na educação. Então uma coisa que marcou muito, quando eu cheguei aqui, vim participar de um treinamento na escola de Emaús de 15 dias. Isso foi em 1984, logo no inicio do ano aqui na escola de Emaús, por disciplina. Foi bom pro bairro (Prof ${ }^{a}$ Alice, entrevista, 2003).
\end{abstract}

Outros cursos foram oferecidos pela escola, ao seu corpo docente (HAGE,1995), nos anos seguintes. A formação continuada de professores realizada no espaço da escola nesse período parece ter-se caracterizado por favorecer a reflexão sobre a própria prática do professor, possibilitando o aprofundamento dos fundamentos teóricos, a correção de distorções e a diminuição das defasagens em relação às finalidades, o encaminhamento coletivo das soluções para problemas emergentes, sendo um processo contínuo de ação-reflexão-ação, levando a um crescimento pessoal e profissional dos professores, ao êxito do trabalho ensinoaprendizagem e fundamentado na concepção dialética da educação (SILVA, 2002).

A formação continuada de professores na Escola de Emaús é discutida neste trabalho, a partir de dois eixos de análise: a Organização de Espaços e Tempos Escolares e As Ações Formativas na Escola, tendo como pontos a considerar o trabalho coletivo, a produção de materiais didáticos, o envolvimento políticosocial e as atividades realizadas no/com o bairro.

Quando analisamos os temas abordados, apontados no estudo feito por Hage, acima referido, vemos claramente duas preocupações apresentadas na Filosofia da Escola. A primeira, uma preocupação com a qualificação técnica das educadoras, no sentido de assumir um trabalho com uma população pobre, de uma área periférica, cuja maioria havia chegado à cidade como consequência do êxodo rural, que tivesse preocupação com a linguagem, o domínio de conteúdos específicos de estudos sociais, matemáticas e ciências, como elementos fundamentais para a qualificação técnica.

A segunda preocupação - e não menos importante - diz respeito à necessidade de aliar a esse fazer técnico competente um fazer político. A dimensão do político se estende desde o compromisso - o estar presente e querer estar presente - até a compreensão das diversas formas de organização social, da importância dessas manifestações na vida de cada pessoa envolvida, da realidade econômica das crianças, jovens e adultos atendidos diretamente no espaço escolar e todas as possíveis contradições que se impõem ao educador popular, tais como a forma de execução da atividade educativa que vai bem além da competência técnica, uma vez que os alunos são extremamente carentes.

\footnotetext{
${ }^{3}$ Médica italiana que desenvolveu o método pedagógico - que leva seu nome -, trabalhando com crianças com
} 
Esse aspecto político é, também, ideológico na realidade estudada. Não pretendo aprofundar aqui os dois conceitos, cujo papel do educador está presente e definido, mas, é necessário para entender o fazer coletivo que se instala na realidade social adversa - aquela em que a escola Cidade de Emaús está inserida - a importância de um fazer fundamentado em uma prática. Paulo Freire (1982, p. 145), referindo-se à conscientização, manifesta-se a favor de uma leitura da realidade que "seja apreendida não como algo que é, mas como devir, como algo que está sendo". Assim, a ação partindo desse trabalho coletivo que se instala na Cidade de Emaús, obriga a entender o papel que a escola deveria assumir e a buscar soluções que possam oferecer um ensino de qualidade. Não bastava apenas saber da pobreza dos alunos, mas, interferir de forma a ajudar a mudar essa realidade. Neste sentido, diz Freire:

Impõem-se, então, discernir a razão de ser desta prática - as finalidades, os objetivos, os métodos, os interesses dos que a comandam; a quem serve, a quem desserve, com o que se percebe, afinal, que esta é apenas uma certa prática, mas não a prática, tomada como destino dado. Desta maneira, na prática teórica, desveladora da realidade social, a apreensão desta implica na sua compreensão como realidade sofrendo sempre uma certa prática dos seres humanos. Sua transformação, qualquer que seja ela, não pode verificar-se a não ser pela prática também (FREIRE, 1982, p. 145).

Apresentamos, a seguir, duas categorias de análise, estabelecidas a partir das falas dos sujeitos investigados: A ORGANIZAÇÃO DE ESPAÇOS E TEMPOS ESCOLARES e AS AÇÕES FORMATIVAS NA ESCOLA. Consideramos esses dois elementos intimamente relacionados ao projeto político pedagógico da escola, cujos documentos examinados e as falas dos sujeitos entrevistados revelam como necessários para a unidade desejada a uma instituição escolar, na diversidade que a caracteriza como tal. Dialogamos com vários autores, a partir das vozes consideradas.

\section{A ORGANIZAÇÃO DE ESPAÇOS E TEMPOS ESCOLARES}

A Escola Cidade de Emaús, desde os primeiros anos, estabeleceu suas diretrizes pedagógicas e administrativas, considerando a partir daí que o administrativo deveria "concorrer para a organização de um ambiente para o estudo de professores (formação) e alunos, na perspectiva de que vários são [...] os espaços através dos quais professores e professoras vão incorporando ideias, conhecimentos e práticas" (LELIS, 1997, p. 128-129).

Esta é a organização dos tempos escolares na Escola de Emaús como é descrito, por exemplo, no trecho de um documento:

Durante o ano de 1984, utilizamos uma série de medidas pedagógicas [como a presença de dois professores regentes por turma] que colaboraram para aumentar sensivelmente a qualidade do ensino, aqui considerado como melhor preparo e desempenho dos professores [...] (MRE, doc.2, 1984). (grifo meu)

O esforço para manter uma organização pedagógica coerente com a proposta pedagógica culminou com um tempo escolar para a formação dos professores (hora atividade). Uma professora, em 1989, chegava a receber 15 horas aulas por semana para formação desenvolvida por meio de encontros semanais, reuniões e estudos coletivos, o que pode ser considerado uma conquista a partir de negociações conjuntas (Escola de Emaús e Escola Cristã do Benguí) junto à Secretaria de Educação. Nas entrevistas, embora tal conquista já tivesse sido perdida há tempos, a professora Alice relembra, de forma bastante enfática, a lembrança e a importância dessa conquista.
[...] sempre em todas as áreas, essa formação era constante. A hora-atividade foi uma grande conquista para a Escola de Emaús e também para a Escola Cristã do Benguí. A gente negociava junto com a direção de Emaús, a coordenação pedagógica da escola. Nós íamos às secretarias e negociávamos juntos e conseguíamos realmente as nossas conquistas para a Escola de Emaús e para a Escola Cristã do Benguí (Prof ${ }^{a}$ Alice, entrevista, 2003).

A formação, durante esses horários para estudo, era desenvolvida de vários modos. Os mediadores dessa formação pertenciam ao quadro da Escola de Emaús, sendo professoras e professores que eram valorizados no seu fazer pedagógico e como referência na sua área.. A preocupação não era apenas possibilitar o estudo teórico, mas fazer desses estudos o suporte para a produção dos recursos didáticos necessários, assegurando o domínio de concepções que embasam a visão sobre o aluno que se desejava formar, suas condições objetivas e subjetivas de vida e a própria interação entre o contexto do 
aluno, a escola e as professoras. O estudo e a discussão constante sobre temas de interesse faziam da escola um espaço de produção e não somente de reprodução do saber.

Com respeito a essa formação profissional permanente no interior da escola, a professora Graziela afirma: "Naquela época, eu achava mais fácil porque tu tinhas mais tempo de te dedicar a estudar mais, pra poder dar [ensinar] pros meninos".

Nessa fala, a formação parece ser compreendida como condição fundamental para assegurar qualidade aos trabalhos que deviam ser desenvolvidos. Não há como negar a importância da formação para o desenvolvimento profissional e a qualificação das ações docentes, muito embora não seja possível esperar uma relação direta entre formação e qualidade do trabalho docente, uma vez que se precisam considerar as condições objetivas e subjetivas de ensino e de aprendizagem. As ações muitas vezes extrapolam à prática docente de sala de aula. Aliás, o período em que este processo formativo acontece coincide com o efervescente tempo de discussão e revisão dos próprios tempos e espaços escolares. Paulo Freire nos apresenta a seguinte ideia sobre o ato de estudar:

\begin{abstract}
Estudar seriamente um texto é estudar o estudo de quem, estudando, o escreveu. É perceber o conhecimento histórico-sociológico do conhecimento. É buscar as relações entre o conteúdo em estudo e outras dimensões afins do conhecimento. Estudar é uma forma de reinventar, de recriar, de reescrever - tarefa de sujeito e não de objeto. Desta maneira, não é possível a quem estuda, numa tal perspectiva, alienar-se ao texto, renunciando assim a sua atitude crítica em face dele (FREIRE, 1982, p. $10)$.
\end{abstract}

Revendo neste trabalho, as várias manifestações de referências a uma época em que as professoras podiam planejar e estudar, de forma remunerada, os conteúdos e as estratégias de ações a serem realizadas em atividades docentes, podemos relacionar as memórias presentes nas diferentes falas a situações marcantes para essas profissionais. As leituras, as conversas, as trocas de experiências e a produção dos materiais que seriam usados em sala de aula, certamente, quando mencionados nas entrevistas, dão a dimensão real da importância da formação no seio de uma escola. $\mathrm{O}$ fazer para essas educadoras precisa ser o fazer correto, o "dar de si para o outro". É o que a Prof.a Graziela parece deixar claro na fala acima, quando diz "[...] estudar mais, pra poder dar pros meninos" (Prof " Graziela, entrevista, 2003).

O problema que os docentes da escola pública em geral têm que enfrentar para assegurar o estudo (formação continuada) não apenas dos conteúdos, mas, também, de técnicas e métodos adequados, e o planejamento de atividades e avaliações parece por em destaque a contradição existente entre os discursos dos programas governamentais, que afirmam o interesse por uma escola pública de qualidade, e a realidade de uma escola que teve ao longo de sua existência uma preocupação com a formação e toda uma ação voltada à busca da qualidade na educação em uma área periférica, trabalhando com crianças oriundas de famílias pobres, algumas delas já exercendo atividades que visam gerar renda para o sustento da família.

Não nos ocupamos aqui a analisar o discurso do Estado, pois não é esse o objetivo deste trabalho. Porém, quando fazemos referência à formação centrada na escola, percebemos essa preparação como sendo parte integrante do ato de educar. Percebemos a contradição entre o discurso que defende a autonomia das escolas, mas não permite uma contrapartida capaz de ofertar suporte material e financeiro à concretização dessa autonomia, aqui analisada sob o aspecto da formação continuada dos educadores e educadoras. Por outro lado, essa formação centrada na escola está diretamente relacionada ao projeto pedagógico de cada instituição escolar, cujos coordenadores devem cuidar de sua concretização, para o que organizam estratégias formativas para o alcance de seus objetivos e metas.

Imbernón (2000), abordando a questão da formação centrada na escola, mostra que esse modelo de preparação institucionalizada surgiu no Reino Unido, em meados de 1970, por meio do "Advisory Council for the Suplly and Training of Teachers", nascido exatamente pela falta de recursos educacionais que assegurassem a formação continuada dos educadores das escolas.

Nossas análises sobre a formação centrada na escola têm abordado a importância dessa formação para atender aos interesses da comunidade sobre as propostas dessa escola, as 
suas possibilidades de auxiliar com atitudes o desenvolvimento dos anseios dos que procuram esse espaço de formação. Por outro lado, a especificidade no tocante à formação dos profissionais da educação que estão a serviço da comunidade, quando analisada, permite perceber o quanto na Escola Cidade de Emaús a preocupação com a realidade da comunidade está presente. Seria, de certo modo, a materialização da ideia apresentada por Imbernón, quando aborda a formação desenvolvida dentro da escola.

\begin{abstract}
A formação centrada na escola envolve todas as estratégias empregadas conjuntamente pelos formadores e pelos professores para dirigir os programas de formação de modo a que respondam às necessidades definidas da escola e para elevar a qualidade do ensino e da sala de aula e nas escolas. Quando se fala de formação centrada na escola, entende-se que a instituição educacional transforma-se em lugar de formação prioritária diante de outras ações formativas. A formação centrada na escola é mais que uma simples mudança de lugar da formação (IMBERNÓN, 2000, p. 80).
\end{abstract}

A construção desse novo paradigma sobre a formação continuada de professores, na experiência aqui apresentada, firma-se como um novo modelo de ação, de concepção sobre a prática de professores diante do desafio de educar, por não se constituir um momento de mero aperfeiçoamento de técnicas e procedimentos. Há, como foi possível perceber nas entrevistas ao longo deste estudo, um comprometimento político impossível de existir sem a presença forte do caráter ideológico, que é o elemento propulsor de todo esse processo, de todo esse projeto em sua raiz, fortemente presente nos documentos que expressam a filosofia de trabalho da Escola, mesmo num período em que a expressão projeto políticopedagógico não existia ou estava apenas sendo introduzida no meio educacional.

Ao estudar os sete pressupostos embasadores do que Imbernón (2000) chama de "paradigma colaborativo", percebemos que a experiência da escola do Benguí viveu desde o seu início essa busca incessante pela integração não apenas entre a escola e a comunidade, mas entre o seu próprio corpo de profissionais.

[...] a escola deve refletir em seu interior a vida do bairro, seus valores, seus costumes, devendo ser um apoio nas suas lutas e reivindicações. [...] a integração será levada a efeito em forma de estudos e discussões conjuntas sobre o processo pedagógico tanto no que concerne ao conteúdo, sua adequação e importância, como na execução do estágio. Esta integração deverá concretizar-se como uma troca permanente entre o corpo docente do 10 e 20 graus (MRE, doc. 1, [198_]).

Essa integração já vinha se apresentando fragilizada, como é destacado num documento de Hage (1992) $)^{5}$ para a direção da escola e que serviu de subsídio para discussões nas reuniões coletivas daquele ano:

Existe um grande isolamento entre o $1^{\circ}$ e o $2^{\circ}$ grau. Esta fragmentação advém principalmente do fato da maioria dos professores e servidores trabalharem no período diurno e alguns somente atuarem no turno da noite. Esta situação tem provocado um afastamento entre o $1^{\circ}$ e $2^{\circ}$ grau, fazendo com que desde o processo de planejamento até avaliação, as atividades ocorram isoladamente prejudicando o desenvolvimento de um processo educativo coletivo e totalizante na Escola.

O propósito de se fazer mudanças na ação demonstrava uma reflexão sentida por todos na Escola, como é apresentado na fala de Graziela quando ela explicita que é necessário o retorno às origens, desse ir e vir e avaliar para avançar, como tantas vezes fizemos.

$\mathrm{Na}$ época em que a escola iniciou, nós trabalhávamos nos dividindo por áreas. [...] eu na época trabalhava só com português e estudos sociais e tinham professoras que trabalhavam ciências e matemática. A nossa formação era justamente essa área. Hoje, [...] sinto essa dificuldade porque eu fiquei responsável pelas 4 matérias. Naquela época, eu achava mais fácil porque tu tinhas mais tempo de te dedicar a estudar mais pra poder dar pros meninos. Hoje tem horas que eu me sinto embananada. Eu fico... na matemática eu me sinto segura, no português eu me sinto segura de dar para meninos. Mas já na área das ciências, na área de estudos sociais eu me sinto um pouco amarrada,

\footnotetext{
${ }^{4}$ 1. A escola como foco do processo "ação-reflexão-ação", como unidade de mudança, desenvolvimento e melhoria; 2. Para a reconstrução da cultura escolar, a escola deve aprender a modificar sua própria realidade cultural; 3. Aposta em novos valores (interdependência, abertura profissional, comunicação, publicizar o ato educativo, colaboração, autonomia, autoregulação e crítica colaborativa); 4. A colaboração como filosofia de trabalho; 5. Processo de participação, envolvimento, apropriação e pertença; 6 . Respeito e reconhecimento do poder e capacidade dos professores; e 7. Redefinição e ampliação da gestão escolar. (IMBERNÓN, 2000, p.80-81).

${ }^{5}$ Comunicação pessoal de 8 de fevereiro de 1992.
} 
até mesmo porque às vezes eu me perco porque eu [...] tenho que sempre olhar no planejamento, ver se realmente já dei ou se estou atrasada. Então, naquela época da formação eu via que a gente tinha como é que se diz, a gente criava mais, tinha mais condições do que hoje, porque tu te dedicava a duas áreas de formação [...]. Então, isso também eu vejo que a gente precisa retomar. [...] eu vejo que nós temos formação, mas eu acho que nós precisamos mais! Ver [...] essa formação de dentro de sala de aula pros meninos [nas áreas específicas] (Prof ${ }^{a}$ Graziela, entrevista, 2003).

A organização dos espaços e tempos escolares, como a permanência de estudos dos professores, de maneira individual ou coletiva, é considerado bom na fala da professora Graziela, acima, expressando saudades de um tempo em que o processo era intenso e organizado no sentido de atender a uma dinâmica do próprio espaço escolar como, por exemplo, a organização dos professores por áreas do conhecimento. A professora Júlia (abaixo) também se refere à organização dos tempos escolares, considerando medida importante para organização do seu tempo individual, para refletir o seu trabalho com os alunos, reforçando a ideia da escola como espaço de formação (VEIGA, 1995).

Assim, ele [o aluno] já acostuma pelo menos com dois professores. E a gente pode [estudar mais] [...] eu fico só com duas disciplinas eu tenho mais tempo pra, organizar melhor a aula. Porque ela já fica com duas eu com duas e ... a gente organiza melhor a atividade que a gente vai passar pra eles (Prof ${ }^{a}$ Júlia, entrevista, 2003).

Em muitas situações, o processo de entrada na Escola passava por um "ritual" de conhecimento da filosofia da Escola e tempo de adaptação ao novo ambiente. Júlia passou por isso quando da sua chegada e, embora relutasse em permanecer na Escola pela distância de sua residência, acabou permanecendo e se engajando na proposta. Essa preparação consistia em uma conversa com a diretora ou outro membro mais experiente da equipe sobre a filosofia da Escola; a professora recém-chegada não assumia de imediato uma turma, mas passava pela experiência de compartilhar uma turma junto com outra professora, na qual ficava mais ou menos dois meses e só então ficava sozinha, assumindo a turma como sua, de fato.

Esse ritual lembra o que Schön (1995) denomina de aprendizagem com um parceiro mais experiente. $\mathrm{O}$ mesmo procedimento é relatado por Gonçalves (2000), ao tratar da formação inicial de professores no Clube de Ciências da UFPA, atribuindo valor formativo à essa parceria com um sujeito já iniciado na filosofia de trabalho e a um tempo inicial de leituras e estudos preparatórios para a assunção de um trabalho diferenciado.

Entrar em um grupo novo, contudo, parece ser um desafio a ser enfrentado pelo sujeito que se propõe a esse novo pertencimento. Júlia, assim como Graziela, titubeara. Diz ela:

Voltei e tornei a conversar com a Gabriela, ela me colocou a filosofia da escola e tudo e eu disse: Eu tenho que encarar essa e logo que eu já que eu peguei uma sala de aula fiquei junto com uma outra professora (Prof ${ }^{a}$ Júlia, entrevista, 2003).

Essa organização do trabalho pedagógico criava, enfim, uma outra forma de relações de trabalho que fazia a diferença na opção da professora em permanecer na escola.

[...] outra coisa que era marcante aqui na escola era a forma como a escola era administrada. Ainda é, mas naquela época era mais marcante, talvez porque fosse novo. [...] a gente passou a fazer o mesmo na Escola Cristã porque também por orientação das pessoas daqui, com o apoio e orientação pedagógica daqui, da direção da escola (de Emaús) lá na Escola Cristã do Benguí (Prof ${ }^{a}$ Alice, entrevista, 2003).

\section{AS AÇÕES FORMATIVAS NA ESCOLA}

Analisando os vários temas tratados durante os estudos coletivos realizados nos mais de vinte anos de experiência com educação formal, percebe-se que a ênfase na ação crítica apresentada de início não obscureceu a visualização da necessidade de formação técnica, que ganha contornos de integralidade no processo pedagógico da Escola. Tudo, entretanto, era decido em conjunto, nas assembleias.

Que eu me lembre, [...] eram discutidos até então nessas assembleias [...] a formação, que formação a gente queria, qual o tipo [...] na semana era discutido e terminava sendo, chegando ao consenso, o período que ia ser e qual o tipo de formação ( $\operatorname{Prof}^{a}$ Alice, entrevista, 2003).

Entretanto, aliadas às questões técnicas, encontram-se também, e talvez de modo preponderante, questões de ordem humanosocial e política, tendo em vista a organização social para o trabalho e produção de renda das 
famílias e a consequente formação de sujeitos cidadãos.

\section{CONSIDERAÇÕES FINAIS}

A discussão realizada neste trabalho possui, de certa forma, ponto de partida em outros estudos que surgiram sobre a Escola. Esses estudos, certamente, não analisaram a questão da formação continuada, mas entendem a Escola como sendo um espaço que deve contribuir para a formação de seus próprios professores.

Tentamos ir além da análise e afirmação de um discurso sobre a qualidade e as potencialidades da escola. Procuramos identificar os elementos constituintes dessa formação, que fazem com que os professores aprendam em sala de aula e a maneira como buscam ir ao encontro de seus alunos, conscientes da importância de reverem e constantemente refletirem sobre suas ações, tendo como objetivo alcançar os melhores resultados de suas turmas (ALARCÃO, 1996).

Percebemos na proposta da Escola Cidade de Emaús que existe uma intervenção, buscando a formação continuada de professores que, nessas mais de duas décadas de existência, vêm fazendo da reflexão e da ação elementos capazes de assegurar um trabalho coerente com a proposta de uma nova e democrática prática educativa. Concordamos com Alarcão (2003, p. 80), quando diz que uma escola reflexiva é um espaço de gestão integrada de pessoas e processos.

É hora de apostar em alternativas de formação, que desenvolvam profissionais reflexivos, que sejam centrados na escola e aproveitem todo o potencial pessoal e físico desses espaços educativos.

Percebemos que é necessário ao educador o conhecimento para eleger - qualitativamente - os recursos que devem ser utilizados como apoio didático/metodológico na sua prática pedagógica. Porém, não o temos como suficiente, sobretudo, quando nos entendemos educadores que estão constantemente aprendendo. Os professores são sujeitos motivadores do processo de ensino e de aprendizagem, mas necessitam atividade de formação continuada porque, como seres humanos, somos inconclusos, como diz Freire:

Como professor crítico, sou um "aventureiro" responsável, predisposto à mudança, à aceitação do diferente. Nada de que experimentei em minha atividade docente deve necessariamente repetir-se. Repito, porém, como inevitável, a franquia de mim mesmo [...] enquanto ser cultural, histórico, inacabado e consciente do inacabamento (FREIRE, 1998, p. $55)$.

As propostas de formação continuada precisam apostar numa conduta reflexiva dos professores em sua atuação como docente. Essa conduta reflexiva leva o professor a ser mais sensível diante das dificuldades que lhe são apresentadas em seu cotidiano, tornando-o mais eficiente nesse processo de engajamento na sua realidade e na de seu aluno. Engajamento que provoca toda uma mudança conceptual do processo ensino - aprendizagem e modificações empreendidas em sua sala de aula (ZEICHNER, 1993).

Os impasses e as dificuldades apresentadas pelos profissionais, no que tange à preparação de suas aulas, principalmente no que diz respeito à avaliação da aprendizagem, são considerações que devem ser questionadas, mais uma vez discutidas em grupo de professores que construam uma autonomia profissional, aliada a uma busca teórica para a compreensão da própria prática (ALARCÃO, 2003).

O que se propõe são ações que levem em conta toda a experiência desses docentes, para que sua formação realmente se efetive.

Alguns dos fatores abordados neste trabalho podem ser destacados como elementos constituintes que devem ser considerados em uma proposta de formação continuada, como o trabalho coletivo (NÓVOA, 1995), o envolvimento político-social e as atividades realizadas no/com o bairro (ZEICHNER, 1993). Por outro lado, diante das transformações aceleradas a que todos estamos submetidos, é arriscado apontar para um modelo de formação que satisfaça a atual conjuntura em que se insere o trabalho educativo das escolas. Porém, independentemente da incursão em certas limitações, suponho que o desenvolvimento de alguns fatores possa ajudar nessa busca relativamente angustiante - de resposta à prática docente nas escolas públicas.

Um desses fatores é a necessidade de que os espaços e tempos escolares sejam pensados e 
discutidos por todos, satisfaçam às necessidades da organização escolar, de maneira a que melhor se ajuste ao processo de formação. Com a introdução desse tipo de discussão fazendo parte de uma estratégia maior da instituição, inclusive da própria rede de ensino da qual a escola faz parte, pode-se dar um passo adiante, ou fazer-se um resgate daquilo que já fora uma experiência de sucesso.

A efetivação desse e de outros fatores precisa estar assegurada no projeto político pedagógico da escola. A estrutura da escola, o papel de seu corpo administrativo e todas as ações que visem a assegurar o processo de formação dos alunos precisam estar ali pensados, instalados, mas, sendo do domínio da comunidade escolar. Portanto, o projeto da escola precisa ser produzido e internalizado pelos sujeitos que a constituem. A experiência da Cidade de Emaús demonstra que, no início, essa prática coletiva existia e ganhava contornos de um projeto que, unificando diferentes pessoas de diferentes experiências sociais e culturais, refletia um compromisso que era marcado pelo político e pelo ideológico, à medida que se propunha a assumir o compromisso de educar filhos de trabalhadores, excluídos da educação formal, em seu próprio espaço de moradia, respeitando seus valores e procurando conquistar junto com eles o direito à dignidade.

\section{REFERÊNCIAS}

ALARCÃO, Isabel. (Org.). Formação reflexiva de professores: estratégias de supervisão. Porto: Porto Editora, 1996.

FREIRE, Paulo. Ação cultural para a liberdade e outros escritos. 6.ed. Rio de Janeiro: Paz e Terra, 1982.

FREIRE, Paulo. A educação na cidade. São Paulo: Cortez, 1991.

FREIRE, Paulo. Pedagogia da autonomia: saberes necessários à prática educativa. 9.ed. São Paulo: Paz e Terra, 1998.

GONÇALVES, Terezinha Valim Oliver. Ensino de ciências e matemática e formação de professores: marcas da diferença. Campinas, 2000. 275p. Tese (Doutorado em Educação: Metodologia do Ensino). UNICAMP.
HAGE, Salomão A. M. Construindo uma escola que interessa as classes populares, análise da proposta político-pedagógica da Escola Cidade de Emaús - Belém - Pará. São Paulo, 1995. 236p. Dissertação (Mestrado em Educação: Supervisão e Currículo). PUC-SP.

HORA, Dinair Leal da. Gestão democrática na escola. São Paulo: Papirus, 1994.

IMBERNÓN, Francisco. Formação docente e profissional: formar-se para a mudança e a incerteza. São Paulo: Cortez, 2000. (Questões da Nossa Época, n. 77)

LELIS, Isabel Alice O M. Magistério primário: tempos e espaços de formação. In: CANDAU, Vera Maria (Org.). Magistério: construção e cidadania. 3.ed. Petrópolis: Vozes, 1997.

MRE. Documento 1 - Filosofia da Escola Cidade de Emaús. Belém, [198_].

MRE. Documento 2 - Oficio ${ }^{\circ} 44$ da Escola Cidade de Emaús. Belém, 1984.

NÓVOA, Antônio. Formação de professores e profissão docente. In: NÓVOA, Antônio. (Coord.). Os professores e sua formação. Lisboa: Dom Quixote, 1995.

SCHÖN, Donald. Formar professores como profissionais reflexivos. In: NÓVOA, Antônio. (Coord.). Os professores e sua formação. Lisboa: Dom Quixote, 1995.

SILVA, Moacyr. A formação do professor centrada na escola: uma introdução - A experiência do vocacional. São Paulo: EDUC, 2002.

SWIFT, Anthony. Crianças para a mudança social - educação para a cidadania de crianças de rua e crianças trabalhadoras no Brasil. Tradução. jan.1998. (Original em inglês).

VEIGA, Ilma Passos Alencastro. Projeto político-pedagógico da escola: uma construção coletiva. In: VEIGA, Ilma Passos Alencastro. (Org.). Projeto políticopedagógico da escola: uma construção possível. 7.ed. Campinas: Papirus, 1995. (Magistério - Formação e Trabalho Pedagógico).

ZEICHNER, Kenneth M. A formação reflexiva de professores: idéias e práticas. Lisboa: EDUCA, 1993. 